\title{
Una aproximación al editorialismo informativo. Análisis de la sección "Política" del diario Público (septiembre- noviembre 2008)
}

\section{An approach to Objetive Editorialism in Spanish Press. Analysis of Público's Political Section (September-November 2008)}

César Mejía Chiang. Universidad de San Martín de Porres (Lima - Perú)

Recibido: 16-XI-2009 - Aceptado: 16-XII-2009

Resumen:

El presente artículo analiza la incidencia del fenómeno del editorialismo informativo en los objetivistas pertenecientes a la sección "Política" del diario Público (septiembre-noviembre de 2008). El estudio del origen y de la configuración de esta peculiaridad estilística (en las noticias y reportajes objetivos) nos aproximará a la comprensión de las páginas políticas de esta publicación, así como identificar su contenido ideológico, su lenguaje y su estructura narrativa.

Palabras clave:

Editorialismo, Prensa española, Géneros de opinión, Géneros informativos, Discurso periodístico, Redacción Periodística, Ética periodística.

Abstract:

This article analyzes the incidence of informative editorialism within objective texts in Público political section (September-November 2008). The origin and the configuration of this stylistic peculiarity approach us to understand the political pages of this newspaper, as well as its ideological content, its language and its narrative structure.

Key Words:

Editorialism, Spanish press, Feature story, Objectivity, Journalistic style, News writing, Journalism ethics. 


\section{Introducción}

El desarrollo de esta investigación responde a los siguientes factores: a) el interés que suscita la aparición de Público, el diario generalista más joven de la prensa española; b) la identificación de rasgos particulares en la redacción periodística de dicha publicación; y c) la incidencia del editorialismo informativo en la sección informativa más importante de este periódico.

Este fenómeno estilístico forma parte del extenso debate en torno a la clásica confrontación entre stories ("sucesos") y comments ("comentarios"). En ese sentido, este estudio no pretende ofrecer una diatriba a estos últimos ni tampoco una apología de los "géneros objetivistas”. Creemos que el derecho a opinar de un medio periodístico es válido en tanto se ajuste al interés público, al respeto a la dignidad de funcionarios y ciudadanos, así como al marco legal que precisamente garantiza la libertad de expresión. Sin embargo, se busca delinear los parámetros que configuran esta práctica redaccional, abocada a la editorialización encubierta y efectiva de textos aparentemente informativos.

\section{Metodología}

Por su naturaleza temática, la sección "Política” permite medir con mayor fiabilidad la intensidad opinante dentro de los esquemas noticiosos y reporteriles. El período de investigación (trimestre septiembre-noviembre) coincide con el primer aniversario de esta publicación (26 de septiembre de 2008), brindando la oportunidad de establecer balances y evaluaciones más exactas. Este trimestre también reflejaría la línea editorial primigenia de Público, establecida por su director Ignacio Escolar, quien fue reemplazado a comienzos del 2009 por Félix Monteira.

La metodología empleada posee un carácter empírico-evaluativo porque detalla la incidencia de contenidos "editorialistas" y "subjetivos" dentro de los cuerpos noticiosos reporteriles de la sección "Política", explicando su estructuración, intencionalidad e interacción con el resto de elementos textuales.

Los principales instrumentos que ayudaron al examen del material fueron las plantillas de observación que cuantificaron el empleo de diferentes géneros periodísticos en la mencionada sección. Del mismo modo, estas herramientas de investigación contribuyeron a identificar los diversos subtemas y tópicos recurrentes en los textos incluidos en las páginas políticas. 


\section{Hipótesis de trabajo}

Los géneros informativos, aparecidos en la sección "Política” del diario Público, poseen algunas características propias de los textos de opinión, conformándose una paradoja estilística denominada "editorialismo informativo", que implica la introducción de juicios tendenciosos y propagandísticos en los párrafos de noticias y reportajes. De esta manera, ambos estilos aparentemente objetivistas explotaron los escándalos políticos y atacaron a los miembros de la oposición política española. Para reforzar dicha tendenciosidad, emplearon un lenguaje exclamatorio, basado en coloquialismos y tonos apelativos.

\section{Breve repaso a los géneros informativos}

Estos textos son vástagos del positivismo y de la revolución industrial ${ }^{1}$, manteniendo una considerable presencia en la prensa actual. Si bien se ha criticado su esquema "lineal" y "unidimensional", su vigencia reside en su perspectiva objetiva y veraz ante los hechos. Las principales especies son la noticia², el reportaje objetivo y la entrevista de declaraciones.

La noticia es la piedra angular de toda tarea informativa, engloba formas simples de redacción, sin depender de las extrapolaciones ni de contextualizaciones. Se limita a enumerar sucinta y jerárquicamente los datos esenciales de un hecho novedoso, de interés general y de cierta relevancia pública (Escribano, 2006: 15). Por su carácter inmediato y pragmático, se exige mucha fidelidad en el acopio de información, traduciéndose en un poco o nulo protagonismo del redactor (Campbell, 2002: 21). Según Martínez Albertos (2001: 288 y 292) lo que más caracteriza a la noticia ${ }^{3}$ es su máxima economía de medios lingüísticos:

1 Mar de Fontcuberta (1995: 72-73) sostiene que el origen de este esquema tuvo una relación intrínseca con la aparición del telégrafo (1840). Dicha invención habría provocado el primer cambio profundo en la redacción periodística, ya que anteriormente, durante el apogeo del "periodismo ideológico", no importaba mucho la disposición y el orden que diferenciara un texto de otro. Los telegrafistas empezaron a componer textos concisos en clave Morse, reuniendo los detalles más importantes de un suceso en un mínimo de líneas. Si el suceso resultaba complejo o contenía datos secundarios, estos eran colocados en párrafos subsiguientes. Esta tendencia estilística se habría acentuado durante la Guerra Civil Estadounidense (1861-1865).

2 En este trabajo consideramos este término como una especie redaccional dentro de los géneros informativos. Si bien en la mayoría de los tratados suelen denominarla "información” (aunque también cabe destacar "despacho", "nota”, "párrafo informativo” o “gacetilla”) creemos que tal expresión no abarca la real dimensión de la noticia. La información sólo comprende datos y detalles acerca de un determinado tema o acontecimiento, los cuales son procesados para integrar el contenido periodístico.

3 En su libro Curso general de redacción periodística: lenguaje, estilos y géneros periodísticos en prensa, radio, TV y cine, este término figura como "información". 
Es el género literario más escueto, más descarnado, más fuertemente ceñido al puro esqueleto del hecho o acontecimiento que se quiere transmitir. Es, diríamos, el género periodístico más rigurosamente objetivo en su propósito teórico y desde el punto de vista de la apariencia formal del lenguaje utilizado por el periodista.

Luis Núñez Ladevéze (1995: 80) no duda en calificarla como una forma de redacción "tecnocrática-científica”, además de su consabido carácter nominal, prepositivo e impersonal ${ }^{4}$. En cambio, Rafael Yanes (2004: 224) la reduce a textos de formatos estándar, que siempre se repiten con la única variación de la actualización diaria. Además de caracterizarse por su brevedad y accesible comprensión, Fernando López Pan (Cantavella y Serrano, 2004: 204) apunta que las noticias emplean varios "recursos de verosimilitud", entre ellos: a) un estilo impersonal, que se traduce en la ausencia de metáforas, analogías, expresiones poéticas y adjetivos de fuerte sentido valorativo; b) el predominio de las cifras, fechas y detalles gráficos dentro del relato; y c) el recurso de la "pirámide invertida".

Durante mucho tiempo, este esquema de interés decreciente, típico de la noticia, fue sinónimo de imparcialidad y honestidad profesional del periodista, así como modelo dominante en todo texto periodístico. En la actualidad, continúa siendo un formato útil para los géneros informativos, aunque referencial para los interpretativos y los de opinión. Su estructura se basa en un primer párrafo ${ }^{5}$ que concentraba la esencia de la noticia. El resto del texto sería un complemento del acontecimiento principal, lleno de detalles, anexos y datos dependientes del hecho principal.

Los reportajes objetivos ${ }^{6}$ reflejarían el proceso de "reportagización" de la noticia en la prensa estadounidense (Parratt, 2003: 107-109), que se acentuó a mediados de 1980. Se caracterizan por aparecer diariamente en casi todas las secciones del diario, sin estar relegados exclusivamente en las ediciones de fin de semana o en los suplementos dominicales. Así, varios temas de actualidad (contenidos también en las noticias) reciben un tratamiento "reporteril", menos superficial y lineal, pese a recibir las mismas presiones de la "hora

En su libro, Introducción al periodismo escrito, el autor denomina a la noticia "informe periodístico".

Carl Warren (1975: 103-108) sugiere que el lead de sumario es la fórmula más sencilla y segura para comenzar la redacción de una noticia, puesto que ayuda a conocer el hecho (“¿Qué?”), el nombre (“iQuién?”), el tiempo (“iCuándo?”), el lugar (“¿Dónde?”) y la causa (“¿Por qué?”). Estas cinco interrogantes, más conocidas como las 5 W’s (por sus iniciales en inglés) muestran un paralelismo directo con los elementos retóricos compilados por Mathieu de Vendôme siglos atrás. Algunos manuales de redacción tienden a añadir una sexta pregunta (“¿Cómo?”), pero esta pregunta suele estar incluida en el “Qué” y otras veces en la resolución del “Por qué” (Martínez Albertos, 2001: 293).

6 Teóricos españoles como Martínez Albertos (2001: 302 y 330), Martín Vivaldi (1993: 65 y 91) y Núñez Ladevéze (1995: 86) coinciden al señalar que el reportaje puede ser preferentemente informativo o interpretativo. 
de cierre”. Sin embargo, esa labor de ampliación informativa no implica su directa homologación con los niveles de investigación y documentación plasmados en los reportajes interpretativos?

Martínez Albertos (2001:302) lo define como un "relato periodístico descriptivo o narrativo de una cierta extensión y estilo literario muy personal en el que se intenta explicar cómo han sucedido unos hechos actuales o recientes". Según este autor, estas virtudes asentarían su "libertad expresiva”, la cual no tiene cabida en la noticia. Sin embargo, advierte que el reportaje no admite comentarios, juicios de valor o cualquier intención editorializante del redactor. Concha Edo (2003: 141) subraya que el factor fundamental para clasificar un reportaje de "objetivo" es la ausencia de interpretaciones y de opiniones personales, pese a ir firmado. Además, debe contar con una "apariencia de objetividad” en el desarrollo de los hechos. Asunción Escribano (2006: 51-52) sugiere que es un formato informativo, con mayor capacidad de realizar descripciones y de modificar ligeramente su estructura formal, basada en la "pirámide invertida".

El cuerpo "estándar" de este tipo de reportaje presenta una "pirámide invertida" más dilatada (Armentia y Caminos, 1998: 186-187). Aparte de la entrada y los despieces complementarios, su estructura implica la ampliación de los detalles contenidos en el lead. Además de este modelo, el reportaje puede adoptar otros tres tipos de estructura. De acuerdo con Warren (Ibídem: 134-140), pueden ser: a) “de acontecimiento”, que presenta una serie de hechos interrelacionados de forma decreciente; b) "de acción”, centrado en las descripciones de las personas o en la narración de incidentes dramáticos; y el c) "de citas”, que incluye algunos extractos de discursos, documentos o entrevistas bajo la forma de declaraciones entrecomilladas o citas indirectas.

Estos textos discursivos ${ }^{8}$ registran actos de habla, sean estos espontáneos (declaraciones de un político a las afueras del Congreso o en actos públicos) o previstos (ruedas de prensa, mesas redondas, coloquios, intervenciones parlamentarias). Dominados por las citas directas, no suelen centrarse en una historia o en una narración: si bien versan sobre acciones, no hay en ellas propiamente una historia que implique una transformación de un estado de cosas (Cantavella y Serrano, 2004: 177). La confección de estos reportajes (Ibídem: 190-194) responderían a los siguientes criterios de redacción:

Federico Campbell (2002: 70) apunta los siguientes rasgos del reportaje interpretativo: a) representa una investigación profunda y sistemática; b) se refiere a una situación general de carácter social, aunque parta de un hecho particular; c) proporciona antecedentes, comparaciones y consecuencias; d) incluye análisis e interpretaciones; y e) establece conclusiones. Estos cinco valores no son frecuentes en los contenidos de los reportajes objetivos, dirigidos a describir y narrar con amplitud un hecho.

8 Con la finalidad de evitar confusiones o equívocos involuntarios, esta investigación evita el empleo del término Quote Story, así como su equivalente en castellano ("reportaje de citas") reemplazándolo por "reportaje discursivo". 
No se sigue el orden cronológico del discurso: las declaraciones son colocadas por orden de relevancia.

Sintesis de las ideas del declarante: el texto discursivo no es un 'resumen' de todo lo que se dijo. Tampoco es un abstract de un informe o base de datos.

Empleo de transiciones entre las citas: ayudan a mantener la fluidez, la claridad y la cohesión.

Atribución de los comentarios e ideas: el redactor debe evitar ambigüedades y confusiones al emplear las citas indirectas.

Las ideas no pueden quedar desasistidas de sus argumentos: evitar la acumulación excesiva de afirmaciones sin los argumentos (expresados por la fuente) que las fundamentan.

\section{Editorialismo y periodismo político}

Los textos de opinión (artículos, columnas, críticas, entre otros) ayudan a definir con mayor claridad la línea editorial de un medio impreso. En teoría, las apreciaciones y valoraciones de los redactores no perseguirían un afán arbitrario o desinformador, sino en fuentes libres y espontáneas de expresión democrática. Carmen Herrero (1996: 107) recalca la preponderancia de los géneros opinantes con el quehacer político y el mantenimiento de la gobernabilidad democrática al afirmar que la opinión es "la superación de la duda", que beneficia tanto al periodista (al permitirle comunicar sus propias ideas) como a los ciudadanos

Este género se complementaría con sus pares informativos e interpretativos, consolidando el papel de los diarios como "instrumentos fundamentales de debate en períodos políticamente conflictivos" (Escribano, 2006: 158) y generándose así el denominado "periodismo político". Contrario a los intereses propagandísticos o partidistas, esta práctica asume una posición alerta y vigilante ante los posibles abusos del poder oficial.

Sin limitarse a ser el rótulo de una sección, implica una labor compleja que defiende la libertad de expresión y los intereses generales de la comunidad, mediante la integridad profesional y el rigor ante las fuentes. Teóricos como Doris Graber (Borrat, 1989: 98-99), Alejandro Muñoz Alonso (1989: 42-44), José Luis Dader (1992: 181-185), Julian Freund (Borrat, 1989: 21-22) y Ángel Benito (Aguilera, 1990: 62-63) han tratado de elucubrar (tabla 1) su capacidad de maniobra dentro de las relaciones de poder: 
Tabla 1. Funciones del periodismo político

\begin{tabular}{|c|c|c|c|c|}
\hline $\begin{array}{l}\text { Doris Graber } \\
\text { Diseminar la infor- } \\
\text { mación. } \\
\text { Implantar la } \\
\text { agenda pública. } \\
\text { Interpretar y co- } \\
\text { nectar. } \\
\text { Proyectar hacia el } \\
\text { futuro y el pasado. } \\
\text { Estimular para la } \\
\text { acción. }\end{array}$ & $\begin{array}{l}\text { Muñoz Alonso } \\
\text { Recogida y presen- } \\
\text { tación de } \\
\text { información obje- } \\
\text { tiva. } \\
\text { Interpretación y } \\
\text { explicación de las } \\
\text { informaciones. } \\
\text { Contribuir a la for- } \\
\text { mación de la } \\
\text { opinión pública. } \\
\text { La fijación de la } \\
\text { agenda política. } \\
\text { Control del go- } \\
\text { bierno y de otras } \\
\text { instituciones. }\end{array}$ & $\begin{array}{l}\text { José Luis Dader } \\
\text { Función anticipa- } \\
\text { dora de normas. } \\
\text { Función social co- } \\
\text { ercitiva de presión } \\
\text { moralizante. } \\
\text { Función de control } \\
\text { informal del poder } \\
\text { político. } \\
\text { Función legitima- } \\
\text { dora del poder. } \\
\text { Función consen- } \\
\text { suadora o de } \\
\text { equilibrio. } \\
\text { Función de diálogo } \\
\text { e intercambio. } \\
\text { Función de estí- } \\
\text { mulo y sugerencia } \\
\text { de acciones. } \\
\text { Función de contra- } \\
\text { punto } \\
\text { antiburocrático o } \\
\text { antirreglamentista. }\end{array}$ & $\begin{array}{l}\text { Julian Freund } \\
\text { Rol de intermedia- } \\
\text { rio neutral o } \\
\text { imparcial. } \\
\text { Rol del "tercero pí- } \\
\text { caro". } \\
\text { Rol del divide et } \\
\text { impera. }\end{array}$ & $\begin{array}{l}\text { Ángel Benito } \\
\text { El conocimiento } \\
\text { mutuo. } \\
\text { El equilibrio social. } \\
\text { Extensión de la } \\
\text { cultura. } \\
\text { Conciencia de pro- } \\
\text { greso. } \\
\text { Defensa de las li- } \\
\text { bertades públicas. } \\
\text { Asentamiento de } \\
\text { la democracia. } \\
\text { La integración so- } \\
\text { cial. }\end{array}$ \\
\hline
\end{tabular}

Fuente: Elaboración propia

Al consolidar los valores democráticos (denunciando intereses ajenos a ellos) elabora y difunde informaciones que construyen puentes de diálogo entre la clase dirigente y la ciudadanía, fomentando la 
participación de esta última en el ámbito público. Como síntoma de la democratización de la sociedad, el periodismo político apela a las virtudes de la lógica argumental y expositiva, diferenciándose de las prácticas persuasivas (tabla 2), que intentan convencer mediante la emotividad y los prejuicios.

\section{Tabla 2. Diferencias y contraposición}

\begin{tabular}{|lll|}
\hline & PERIODISMO POLÍTICO & EDITORIALISMO INFORMATIVO \\
\hline Mensaje & $\begin{array}{l}\text { Aprovecha las virtudes de la lógica } \\
\text { argumental. }\end{array}$ & $\begin{array}{l}\text { Explota el lenguaje emocional, prejuicios } \\
\text { y figuras estereotipadas. }\end{array}$ \\
\hline Objetivo & $\begin{array}{l}\text { Asumir una posición alerta y vigilante } \\
\text { ante los abusos del poder oficial. }\end{array}$ & $\begin{array}{l}\text { Secundar intereses partidistas y } \\
\text { desinformativos. }\end{array}$ \\
\hline Método & $\begin{array}{l}\text { Rigor ante las fuentes y comprobación } \\
\text { de los hechos. }\end{array}$ & $\begin{array}{l}\text { Negligencia del redactor y su escaso } \\
\text { conocimiento de los géneros. }\end{array}$ \\
\hline Resultado & $\begin{array}{l}\text { Fomentar el diálogo entre los } \\
\text { gobernantes y la ciudadanía. }\end{array}$ & $\begin{array}{l}\text { Afectar la credibilidad del diario y la } \\
\text { profesión en general. }\end{array}$ \\
\hline
\end{tabular}

Fuente: Elaboración propia

El editorialismo informativo posee una intencionalidad distinta. Con la finalidad de defender una ideología o doctrina determinada, esta práctica introduce valores y comentarios afines en textos informativos de forma encubierta. De este modo, la misión originaria de los textos opinantes (brindar apreciaciones responsables, orientar a la opinión pública, defender los derechos ciudadanos) se corrompe al obedecer intereses partidistas. Asimismo, esta operación desinformativa se consolida por la negligencia del redactor y su escaso conocimiento de los géneros periodísticos, evitando así una mejor elaboración del mensaje.

Esta práctica está encarnada en la selección y explotación desmedida del carácter apelativo de las citas directas que figuran en algunas noticias y reportajes objetivos, los cuales se limitan a reproducir despreocupadamente las palabras de otro, sea por la relevancia social o el nivel de pericia de la fuente. Si bien el uso de citas es vital para dotar de credibilidad a los textos informativos, así como en "baluarte defensivo" del periodista para eludir responsabilidades y protegerse de acusaciones (Cantavella y Serrano, 2004: 203-204), la superabundancia de estas piezas periodísticas pueden ser aprovechadas por los agentes políticos, quienes las convertirían en herramientas útiles para defender una ideología o un partido determinado. Ante el peligro de que el periodismo político degenere en una mera extensión de estrategias desinformativas y propagandísticas, resulta necesario establecer una cobertura política y parlamentaria más mesurada 
y ecuánime, sin depender excesivamente de la reproducción de los comentarios y descargos de las figuras políticas, la mayoría de ellas poco imparciales y dispuestos a defender sus propios intereses. Si bien no existe una objetividad absoluta y "aséptica” (ya que la percepción de la realidad no puede librarse totalmente de los prejuicios personales del sujeto cognoscente), creemos arriesgado y contraproducente alentar un relativismo metodológico que niegue toda responsabilidad del comunicado: a largo plazo, el "editorialismo informativo" afectaría a la credibilidad del diario y de la profesión en general.

\section{Ideología de Público}

Público es un diario de pago madrileño perteneciente al Grupo Mediapro-Globomedia. Dirigida por Jaume Roures, esta corporación mediática se ha caracterizado por atraer a las audiencias españolas con mensajes polémicos e impactantes. Tal intencionalidad podemos encontrarla en la señal televisiva La Sexta, que también forma parte de esta corporación mediática. Los primeros números de Público en el mercado, aparecidos en meses previos a las elecciones generales de marzo de 2008, se caracterizaron por su exacerbado tono exclamatorio y su sensacionalismo político, sin dudar en su apoyo a la reelección de Rodríguez Zapatero.

Por ese motivo, no sorprende que esta publicación se presente a sí misma como un diario de izquierdas, que contaría con un renovado y beligerante "progresismo", menos anquilosado que el defendido por El País. En el suplemento especial de su primer aniversario, este diario también revelaría su interés en calar en los sectores juveniles y femeninos, de nivel educativo superior o universitario, sensible ante la coyuntura política. Rafael Puig (Público, 2008a: 4), jefe de la sección “Opinión”, brinda más detalles al respecto:

Joven: lo imaginábamos joven, pero no por ello lobotomizado (como lo ve el resto de la prensa). Aunque los mayores preferirían que no fuera así, se puede ser joven y tener interés en la actualidad, la política, el análisis o la economía.

Más de izquierdas: los periódicos que existían ya formaban parte del sistema, eran instituciones: ¡pero si llevan décadas comiendo con los políticos a diario! Los langostinos y el compadreo entumecen bastante el sentido crítico.

Más mujeres: en España leen más las mujeres, pero la prensa veterana aún es cosa de hombres, escrita por y para señores de cierta edad [...] Ni a los jóvenes ni a las mujeres se les supone ni interés ni capacidad de leer la prensa 'seria'. 
Este interés por calar en los sectores apegados al pensamiento de izquierda estuvo acompañado de una amplia diversificación temática (abundante contenido dedicado a las ciencias, a las artes y al entretenimiento), una generosa política de promociones y obsequios (DVD’s, libros) y numerosos enlaces a la edición digital (cuñas). Contando con estos rasgos, este diario buscó congeniar con la nueva generación de lectores, apostando también por un diseño visualmente atractivo, enlaces a la versión digital y a un lenguaje coloquial.

En el suplemento especial del primer número se expresa abiertamente el compromiso con el "progreso"9 (Público, 2007a: 17-32) y con otras "banderas ideológicas" que hacen referencia a la igualdad, la integración cultural, la protección del medio ambiente, la laicidad, entre otras. Un año más tarde Público (2008a: 6-48) se lanza abiertamente a la defensa del derecho a la eutanasia, al aborto, así como al deporte "limpio" y a la Ley de memoria histórica.

Otro de los aspectos claves para identificar la ideología de Público es la posición política de su primer director, Ignacio Escolar. Otrora redactor de PRISA y popular blogger, este personaje (Escolar, 2007: web) intentó erigirse como un periodista abierto a la discusión de temas "tabú" en España, tales como el retorno al sistema republicano y la explotación laboral de los inmigrantes.

\section{Balance de contenidos}

Las noticias y los reportajes objetivos fueron los textos predominantes en las páginas políticas de Público ${ }^{10}$. Durante el trimestre analizado alcanzaron un promedio de aparición del 80\% (tabla 3) superando largamente la cantidad obtenida por otros géneros dentro de esta sección.

9 Del latín progressus, participio de progredi (“ir hacia adelante”), define al partidario de "ideas avanzadas”. En la Ilustración sirvió para denominar al perfeccionamiento gradual y constante de la humanidad mediante el conocimiento científico. En el siglo XIX, este término se tradujo en el apoyo al sistema republicano, a la libertad de expresión y al derecho al sufragio. Igualmente, implicaba ser cosmopolita y de mentalidad racional, alejada de prejuicios religiosos. A mediados del siglo XX, este vocablo se alió a los programas políticos keynesianos surgidos durante la posguerra. En nuestros días, la “izquierda progresista” se posiciona contra el neoliberalismo económico, condenando la miseria mundial, la intolerancia cultural y religiosa, así como los graves daños al medio ambiente.

10 Las cifras porcentuales se obtuvieron al contabilizar los textos (y no calculando las áreas que ocupaban en la página) a fin de conocer la cantidad de los géneros periodísticos empleados. 
Tabla 3. Géneros periodísticos

\begin{tabular}{|lcccc|}
\hline SECCIÓN “POLÍTICA” & DIARIO PÚBLICO & & & \\
\hline & Septiembre 2008 & Octubre 2008 & Noviembre 2008 & $\begin{array}{c}\text { Promedio } \\
\text { trimestre }\end{array}$ \\
\hline Noticias y reportajes objetivos & $81 \%$ & $79 \%$ & $76 \%$ & $80 \%$ \\
\hline Crónicas & $5 \%$ & $8 \%$ & $6 \%$ & $6 \%$ \\
\hline Entrevistas & $4 \%$ & $3 \%$ & $6 \%$ & $4 \%$ \\
\hline Reportajes especiales & $2 \%$ & $2 \%$ & $2 \%$ & $2 \%$ \\
\hline Sueltos & & & & $6 \%$ \\
\hline ("Punto de vista”) & $6 \%$ & $6 \%$ & $3 \%$ & $2 \%$ \\
\hline Otros textos & $2 \%$ & $2 \%$ & & \\
\hline
\end{tabular}

Fuente: Elaboración propia

Conforme a la tabla 4, a lo largo del trimestre se observó una cobertura considerable de la labor de la oposición política (30\%), con especial atención al Partido Popular y a sus principales líderes.

Tabla 4. Temáticas

\begin{tabular}{|lcccc|}
\hline SECCIÓN “POLÍTICA” & DIARIO PÚBLICO & & & \\
\hline & Septiembre 2008 & Octubre 2008 & Noviembre 2008 & $\begin{array}{c}\text { Promedio } \\
\text { trimestre }\end{array}$ \\
\hline Gobierno socialista & $26 \%$ & $18 \%$ & $22 \%$ & $22 \%$ \\
\hline Oposición política & $31 \%$ & $30 \%$ & $28 \%$ & $30 \%$ \\
\hline Comunidades autónomas & $26 \%$ & $25 \%$ & $20 \%$ & $24 \%$ \\
\hline Actividad parlamentaria & $9 \%$ & $17 \%$ & $19 \%$ & $15 \%$ \\
\hline Lucha contra terrorismo & $8 \%$ & $10 \%$ & $11 \%$ & $9 \%$ \\
\hline
\end{tabular}

Fuente: Elaboración propia

Los géneros informativos exhibieron dos tendencias marcadas (gráfico 1). Un primer grupo contendría un mayor valor informativo (57\%), exhibiendo un estilo claro y sencillo. Esto fue apreciable en las noticias, caracterizadas por sus modestas extensiones. 


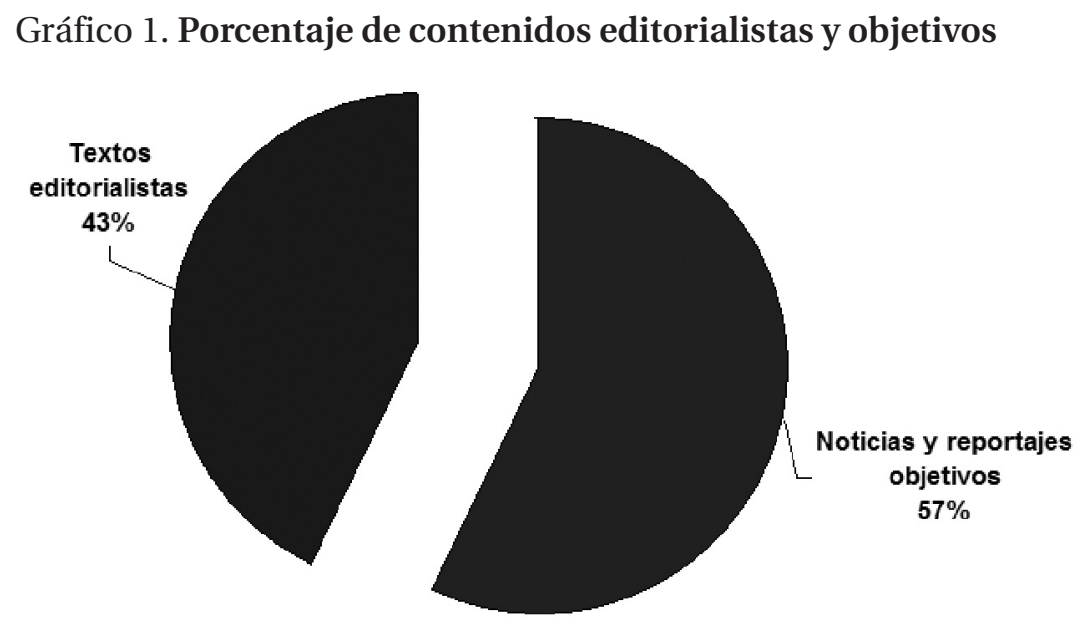

Fuente: Elaboración propia

En cambio, un segundo grupo de textos (43\%) trazó una campaña propagandística que respondía claramente a los alineamientos ideológicos y partidistas de esta publicación. Como observaremos en el siguiente apartado, Público explotó el carácter discursivo de muchos reportajes, llevándolo a niveles exclamatorios y apelativos. Además, insistió en la introducción sutil de juicios de valor en formatos objetivos. 
Tabla 5. Temáticas por naturaleza objetiva/editorialista

\begin{tabular}{|c|c|c|c|c|c|}
\hline \multicolumn{2}{|c|}{ SUBTEMAS EN SECCIÓN “POLÍTICA” } & \multicolumn{3}{|c|}{ DIARIO PÚBLICO } & \multirow[b]{2}{*}{$\begin{array}{l}\text { Promedio } \\
\text { trimestre }\end{array}$} \\
\hline & & $\begin{array}{c}\text { Septiembre } \\
2008\end{array}$ & $\begin{array}{c}\text { Octubre } \\
2008\end{array}$ & $\begin{array}{c}\text { Noviembre } \\
2008\end{array}$ & \\
\hline \multirow{5}{*}{$\begin{array}{l}\text { Noticias y } \\
\text { reportajes } \\
\text { objetivos }\end{array}$} & Gobierno socialista & $29 \%$ & $19 \%$ & $21 \%$ & $23 \%$ \\
\hline & Oposición política & $26 \%$ & $25 \%$ & $26 \%$ & $26 \%$ \\
\hline & Comunidades autónomas & $27 \%$ & $27 \%$ & $22 \%$ & $25 \%$ \\
\hline & Actividad parlamentaria & $7 \%$ & $15 \%$ & $15 \%$ & $12 \%$ \\
\hline & Lucha contra terrorismo & $11 \%$ & $14 \%$ & $16 \%$ & $14 \%$ \\
\hline \multirow{5}{*}{$\begin{array}{l}\text { Textos } \\
\text { editorialistas }\end{array}$} & Gobierno socialista & $26 \%$ & $14 \%$ & $18 \%$ & $19 \%$ \\
\hline & Oposición política & $40 \%$ & $49 \%$ & $44 \%$ & $45 \%$ \\
\hline & Comunidades autónomas & $22 \%$ & $20 \%$ & $16 \%$ & $19 \%$ \\
\hline & Actividad parlamentaria & $6 \%$ & $12 \%$ & $17 \%$ & $12 \%$ \\
\hline & Lucha contra terrorismo & $6 \%$ & $5 \%$ & $5 \%$ & $5 \%$ \\
\hline
\end{tabular}

Fuente: Elaboración propia

En la tabla 4 se pueden apreciar las preferencias temáticas de ambos grupos: mientras que el primero posee una cobertura más regular y proporcionada en los cinco tópicos políticos identificados (oficialismo, oposición y autonomías registran un rango de 23-26\%), el segundo grupo "editorialista" se concentra en la oposición política (45\%), superando otro subtemas como el gobierno socialista (19\%) o la actividad parlamentaria (12\%).

\section{Análisis de textos periodísticos}

Si bien muchas de las noticias de Público se caracterizaron por su brevedad y formalidad, algunas de éstas escaparon de los parámetros objetivistas. En "El PP insiste en que privatizará Telemadrid” (6/IX/2008, p. 15) se emplean dos expresiones muy coloridas ${ }^{11}$ para describir la naturaleza corporativa de este canal de televisión:

11 El empleo de las cursivas en las citas (que no aparecen en el original) nos servirá para destacar el empleo de coloquialismos, barbarismos, extranjerismos y demás rasgos informales en la redacción. 
Esta misma idea estuvo presente en los programas del partido en 1991 y 1995, pero cayó en saco roto cuando Gallardón llegó a la Comunidad. En 2000, el hoy alcalde de la capital lo intentó de nuevo, pero el entonces presidente, José María Aznar, le paró los pies al asegurar que no tenía previsto modificar la ley.

Del mismo modo, en "El PP no se decanta entre Obama y McCain” (2/IX/2008, p. 19) aparecen algunas frases irónicas que intentan retratar la actitud del PP ante las elecciones estadounidenses:

El PP dice que le da igual que gane Barack Obama o John McCain [...] Esa es su postura y para demostrar su ecuanimidad ha enviado una delegación de representantes a las convenciones tanto del Partido Republicano como del Demócrata [...] Mientras Aguirre no tiene problemas en tomar partido, Rajoy prefiere mantenerse neutral y dice no asistir porque no le viene bien.

En la noticia titulada "Rajoy pide al Gobierno que imite a EEUU” (5/X/2008, p. 22) se describe al líder gallego como un político sin ideas originales, reiterativo en sus críticas, aparentemente infundadas, acerca de la situación económica:

Rajoy hizo ayer una aparición fugaz -poco más de 20 minutos- en la inauguración del X [Congreso] Regional de Cantabria. Con ligeras variaciones, su discurso sonó al de los últimos días: España está inmersa en una grave crisis económica y el Gobierno se mantiene de brazos cruzados [...] En esta ocasión, Rajoy optó por dar al presidente del gobierno nuevas recetas: la de imitar a Estados Unidos en su forma de hacer frente a la crisis y la de plantear 'alguna iniciativa' en el seno de la Unión Europea.

Dentro de la estructura de los textos discursivos ${ }^{12}$ proliferaron declaraciones polémicas (generalmente firmadas por el entonces vocero del PSOE, José Blanco) y frases valorativas. En "Blanco insta al PP a abandonar su 'patriotismo de pacotilla' (13/X/2008, p. 19) dicha conjunción se advierte desde la entrada:

El número dos del PSOE, José Blanco, tuvo ayer uno de esos días placenteros para hilar un discurso cargado de argumentos. Y todo gracias al último patinazo del líder del PP con el 'coñazo' del desfile: 'Ya sabíamos que Rajoy tenía principios de quita y pon. Ahora ya sabemos que sus sentimientos son también de quita y pon'.

En el siguiente párrafo se incluyen más valoraciones tendenciosas, entremezcladas con citas indirectas que exhiben acusaciones y apreciaciones negativas hacia el PP:

Blanco había pensado otro discurso para clausurar el congreso del Partido Socialista de Cantabria, pero lo tuvo que modificar por el desliz de Rajoy, con la credibilidad por los suelos. El número dos del PSOE recordó que ni

12 Dícese de las noticias y reportajes que albergan extractos de discursos, declaraciones entrecomilladas o citas indirectas de determinadas personalidades o protagonistas de los hechos. La presencia de estas fuentes declarantes o entrevistadas sería crucial para dotar de credibilidad a la información publicada. 
España se ha roto, como decía el jefe de la oposición antes del 9-M, ni el país está en una ‘situación de emergencia nacional', como afirma el PP.

Los espacios reporteriles de Público sirvieron para plasmar una serie de críticas contra el Partido Popular. Esta intención se puede comprobar en "Las 'miniprimarias' del PP nacen muertas" (11/XI/2008, pp. 18-19), con un titular que ya exhibe de antemano una apreciación desaprobatoria. Esta denuncia es resaltada en el subtítulo, que reza de la siguiente manera: "En los diez congresos regionales convocados con los nuevos estatutos se ha presentado un único candidato al cargo de presidente / El aparato del partido sigue controlando los procesos de elección”. Para reforzar esta tesis se reseña el caso madrileño:

El primer congreso regional en el que se testaron los nuevos estatutos fue el madrileño. No hizo falta campaña: la presidenta de la Comunidad de Madrid, Esperanza Aguirre, fue la única candidata. Nadie se atrevió a enfrentarse a ella. Ni siquiera el círculo del alcalde madrileño, su eterno rival.

Otros reportajes se encargaron de relativizar los acercamientos entre el principal partido de la oposición y las agrupaciones nacionalistas. En "Los nacionalistas no se creen el cortejo del PP" (8/IX/2008, p. 18) se hace palpable el supuesto escepticismo y resquemor de estos dirigentes políticos:

Incrédulos. Así es como los nacionalistas observan los tímidos gestos de acercamiento del PP. No les es fácil olvidar la demonización a la que les sometieron durante la pasada legislatura y consideran que el giro emprendido por la derecha es una cuestión de formas, pero no de fondo.

Este tipo de comentarios se prolonga en el siguiente párrafo, donde se resume el hipotético desempeño político del líder del PP, planteando generalidades y suposiciones sin base:

Desde que perdió las elecciones, Mariano Rajoy no ha hecho más que repetir que está dispuesto a dialogar con todas las fuerzas políticas. Las formaciones nacionalistas con representación en las Cortes desconfían del cortejo del PP y creen que responde a una estrategia calculada.

Esta última idea es retomada en "Rajoy esquiva Irak porque está ocupado con Georgia” (2/IX/2008, p. 19). El peculiar lead se encarga de "develar" el proceder "maquiavélico" del PP para obtener la victoria electoral en el 2012:

Mariano Rajoy ha iniciado el curso político activando su nueva estrategia. No quiere que su partido haga sangre con el accidente aéreo, piensa dialogar con todas las fuerzas políticas, está dispuesto a colaborar con Zapatero ‘en todo’ y centrará su discurso en la economía con el objetivo de ganar nuevos votantes. 
Siguiendo esa lógica “conspirativa”, el debate presupuestario y de financiación económica sería el principal "caballo de batalla" de este partido. En "Rajoy carga contra los presupuestos pese a decir que los negociará 'en serio”” (1/X/2008, p. 27) se reflejaría la aparente vehemencia y contradicciones del dirigente gallego:

El líder conservador hizo ayer filigranas para erigirse en hombre de Estado sin renunciar a ejercer la oposición. Proclamó que su intención era arrimar el hombro en materia económica pero sus palabras chocaban con los hechos, porque no hizo una sola concesión a sus adversarios políticos. Para el PP, nada, ni una coma, se salvaba del texto del proyecto de ley.

En el siguiente párrafo fluirían varios entrecomillados donde se retoma la proposición general del titular: el "doble discurso" de Rajoy a la hora de establecer diálogo con el oficialismo:

Todos los calificativos sonaban ayer a poco a la hora de describir los Presupuestos de 2009. Para Mariano Rajoy eran 'increíbles', 'resignados', 'ayunos de liderazgo', 'inútiles para salir de la crisis', 'contraproducentes'... Éstas eran tan sólo algunas de las críticas que el líder del PP lanzó contra las cuentas del Estado, mientras anunciaba su disposición para hablar con el presidente del Gobierno, en el encuentro que se celebrará antes de una semana en La Moncloa. Eso sí, 'en serio', porque Rajoy dijo que no quería sentirse 'utilizado', o ir 'para la foto'.

De igual modo, las sugerencias de la oposición para paliar la crisis financiera fueron sistemáticamente rebatidas en "Las 25 medidas populistas del PP" (3/IX/2008, p. 17). Reproducimos una de las réplicas editorialistas de Público:

El PP propone contener la subida de las tarifas eléctricas, para rebajar los costes de las empresas y aliviar los presupuestos de las familias, siguiendo la estrategia que desarrollaron [los populares] durante sus años de Gobierno. Aquello fue un caramelo envenenado: se limitó la subida de la luz, pero a las compañías eléctricas se les reconoció el coste que aquello suponía. Es lo que se conoce como el déficit de tarifa que están pagando ahora los usuarios y seguirán pagando en los próximos años.

Otros miembros del Partido Popular también fueron blanco de acusaciones. El alcalde de Madrid, Alberto Ruiz-Gallardón, fue el protagonista del reportaje titulado "Los coches de lujo disparan el juego de la doble moral” (30/X/2008, p. 21), publicado durante los escándalos de despilfarro de Ernest Benach y Pérez Touriño.

Público confirmó que el coche de Gallardón, otro Audi A8 igualmente lujoso, potente y blindado, costó aún más que el de Touriño: 591.624 [...] Nadie ha acusado a Gallardón de predicar la austeridad mientras viaja en un automóvil cuyo precio daría para mantener a 25 familias, más en tiempos de crisis: ese ha sido el argumento cumbre del PP gallego en el caso de Touriño. ¿Dirigirá Feijóo a Gallardón algún reproche, o son de quita y pon a conveniencia las 25 familias de la metáfora alimentaria? 
En "Zarzalejos acusa a la 'miserable' Aguirre de urdir su cese en ' $A B C$ ” (28/X/2008, p. 18) se acumulan comprometedoras calificaciones del ex director del mencionado diario contra la presidenta de la Comunidad de Madrid, sin hacer un esfuerzo significativo por reducirlas o tamizarlas:

El ex director señala a la presidenta de la Comunidad de Madrid como la responsable de su destitución por Ángel Expósito y no se corta un pelo al dedicarle un rosario de calificativos. 'Autoritaria', 'vanidosa', 'ignorante', 'poco leída', 'miserable', 'intervencionista', 'intolerante', 'impertinente'... son algunos adjetivos que Zarzalejos le dedica a Aguirre en la extensa entrevista en Capçalera.

En “Blanco: 'Madrid tiene los peores políticos al frente”" (8/IX/2008, p. 16) se busca debilitar la credibilidad de la mencionada dirigente popular, previo trasfondo de un cónclave socialista:

El PSOE no da tregua en Madrid. En tres días de Congreso, Esperanza Aguirre no se ha caído de la boca de los socialistas. Uno tras otro, del ámbito madrileño o federal, todos sus líderes han cargado contra la presidenta madrileña, convirtiéndola en una suerte de bestia negra para el nuevo socialismo. 'Esperanza Aguirre es un riesgo para la salud y la educación de los madrileños', insistía su secretario general, Tomás Gómez.

En el reportaje titulado "Aguirre desautoriza la oposición que hace Rajoy” (15/IX/2008, p. 15) no sólo se resalta la sinceridad y el "arrojo" de la "lideresa" al abordar ciertos temas polémicos, sino también su desacuerdo con la "estrategia general” de la oposición:

La presidenta de la Comunidad de Madrid ha apuntado a la línea de flotación de la labor de oposición que desarrolla Mariano Rajoy. Esperanza Aguirre asegura que no cree que las iniciativas del presidente del Gobierno, José Luis Rodríguez Zapatero, acerca del aborto o la eutanasia, así como de la memoria histórica, sean sólo 'cortinas de humo' para tapar la crisis económica.

El antagonismo Aguirre/Gallardón es explotado en "Aguirre culpa a Gallardón de las inundaciones" (24/X/2008, p. 17), que hace referencia a las riadas que afectaron el sureste de la capital. La entrada se limita a resumir algunos incidentes anteriores de esta "relación conflictiva":

Ahora que la crisis ha hecho que el alcalde de Madrid abandone los planes de remodelar el eje Prado-Recoletos que tanto enfadaba a Aguirre, la lideresa ha encontrado otro campo de batalla para lidiar con su eterno rival.

Esta supuesta "lucha interna” en el seno del Partido Popular también se sugiere en "El equipo de Gallardón celebra 'la primera derrota' de Aguirre” (13/XI/2008, p. 16). Basado en declaraciones y fuentes vagas, se sostuvo fervientemente la desunión dentro del principal partido de la oposición:

En el Ayuntamiento de Madrid piensan que es 'la primera batalla de poder que pierde Esperanza Aguirre’ desde que es la presidenta de la Comunidad de Madrid. Y desde el Gobierno regional afirman que no hay 'ninguna 
guerra con Alberto Ruiz-Gallardón porque de lo que se trata es de cumplir la ley’. Pero la pelea entablada en torno a la presidencia de Caja Madrid ha logrado 'romper por completo' al PP madrileño, según admiten fuentes conservadoras.

En medio de esta "batalla partidista", Público aprovecha en acuñar nombres a los dos bandos "enemigos" para narrar una accidentada reunión:

Ajenos a los recados, aguirristas y gallardonistas siguen midiendo sus fuerzas. Tras la reunión de la Asamblea de la caja, el pasado lunes, donde se aprobó la lista de entidades representativas que formarán parte de sus órganos de gobierno, el equipo de Aguirre cargó contra los ediles de Gallardón por apoyar a Blesa.

En “El PP llama a Zapatero ‘la mayor desgracia’ de España” (11/X/2008, p. 21) las réplicas de los voceros y dirigentes populares aparecen caricaturizadas y simplificadas. Recogemos el párrafo dedicado al vocero del Partido Popular:

Cada uno tuvo su minuto de gloria y, aunque el motivo real del encuentro era dar con 'soluciones para la crisis', casi todo se centró en cargar contra Zapatero. Abrió la sesión el vicesecretario general de Comunicación, Esteban González Pons, recordando la privatización de Rumasa. Dijo que aquello le parecía una 'propina' en comparación con el fondo del gobierno y pidió meter el dinero ‘en una hucha de cristal.

Las apariciones de José María Aznar en las páginas políticas de Público respondió a dos motivos esenciales: a) recoger sus apreciaciones acerca del actual líder de su partido; y b) protagonizar evaluaciones retrospectivas, normalmente desfavorables a su gobierno (VII Legislatura). Un ejemplo del primero sería "Aznar no da tregua a Rajoy: 'En política no se está para empatar”” (23/XI/2008, p. 21). Con un titular exclamatorio, este reportaje discursivo reunió comentarios amargos contra su "sucesor":

Cinco meses después de que José María Aznar sacudiera con saña a Mariano Rajoy desde la tribuna del XVI Congreso Nacional del PP, ayer se mostró igual de combativo con su sucesor al frente del partido. Ocurrió en la clausura del XI cónclave de las Nuevas Generaciones (NNGG) de Madrid.

El siguiente párrafo ampliaría dicha afirmación al colocar los reproches y las declaraciones más impactantes de Aznar, acompañadas de cierto aire especulativo:

El ex presidente del Gobierno no hizo ninguna mención expresa a Rajoy, que había excusado su presencia por tener comprometida la asistencia al congreso del PP de Almería, pero no hacía falta ir muy lejos para concluir quién era el destinatario de gran parte de su discurso. 'Una cosa es determinante: si salís a jugar, si salís al partido, salid a ganarlo', recomendó, para después añadir el remate: 'En política no se está ni para empatar ni para heredar'. Con esas palabras, el presidente de FAES se sumaba a la tesis de algunos críticos del PP que acusan a su líder [Rajoy] de pasividad, de estar a la espera de heredar la presidencia del Gobierno de Zapatero sin más. 
Una amplia diatriba a su política exterior (intervención militar en Irak) puede observarse ampliamente en "Aznar se erige en paladín de Bush: 'Nos deja el legado de la libertad”" (15/XI/2008, p. 18). Las primeras líneas de este reportaje discursivo ya contienen duros calificativos:

Aznar es tozudo. Ni la tímida autocrítica que ha entonado George W. Bush respecto a Irak es capaz de cambiar su opinión. Si el presidente estadounidense ha cedido algo ante sus detractores, Aznar se enroca.

El texto no cesa en sus graves ataques al ex mandatario, quien aparece retratado como un político aparentemente más reaccionario que el propio Bush:

Convertido en paladín del presidente saliente hasta un punto que ningún otro líder occidental ha alcanzado, Aznar siguió ayer, más papista que el Papa, defendiendo la guerra y al propio Bush. En un artículo publicado por el diario francés Le Figaro, el ex presidente afirma sin complejos: 'Nos deja su mejor legado, el legado de la libertad.

El segundo párrafo trata de brindar unos aparentes datos de antecedentes. Sin embargo, este peculiar background está teñido de un tono sarcástico y de un corrosivo humor:

La historia viene de lejos. Después de años compartiendo cumbres, en enero de 2004, George Bush y José María Aznar sellaron su relación. Con el despacho oval como escenario, una mirada cómplice y una frase amable bastó. 'Nuestra amistad va mucho más allá de nuestros cargos oficiales', prometió Bush.

Asimismo, se intenta denunciar y desacreditar las apreciaciones de Aznar al contraponerlas con los "crímenes de guerra" perpetrados en Medio Oriente durante la administración de George W. Bush:

Aznar sólo habla de la libertad en términos genéricos. Escándalos como el de Abu Ghraib o el programa de escuchas telefónicas, la dimisión de colaboradores, el recorte de libertades ejercido bajo el paraguas de la guerra contra el terror o la cárcel de Guantánamo no se mencionan en el texto [...] Ni siquiera la controvertida Ley Patriota, que recorta ciertos derechos civiles, le hace dudar de las intenciones de su amigo.

Mientras que las principales figuras del Partido Popular son retratadas de forma negativa, este diario erige una imagen más favorable y límpida de José Luis Rodríguez Zapatero. En "Zapatero potenciará la Alianza de Civilizaciones al margen de EEUU” (15/IX/2008, p. 14) se resalta la aparente relevancia del líder del PSOE en el escenario mundial:

Los esfuerzos de la Administración estadounidense del presidente George W. Bush -a pesar de sus incumplidas buenas intenciones iniciales- por arrinconar la iniciativa de Rodríguez Zapatero han resultado infructuosos. 
En el plano nacional, el presidente de Gobierno resaltaría por su carácter “conciliador” y “dialogante”. En "Zapatero pide calma en el debate de la financiación” (12/IX/2008, p. 19) también se reflejaría otra virtud: su profundo "estoicismo" y esperanza para capear la recesión económica:

Todo bajo control del Gobierno. Ni la sangre va a llegar al río por el tira y afloja entre las administraciones autonómicas y la central a causa de la financiación, ni la temida recesión, anunciada el miércoles por la Comisión Europea, provocará la hecatombe en los bolsillos españoles.

El reportaje titulado "El PSOE atribuye a Zapatero el liderazgo mundial ante la crisis" (22/XI/2008, p. 18) aparece estructurado como una apologética "declaración de principios”, ya que se limita a reproducir el apoyo de los socialistas a su líder desde la entrada:

El Gobierno de España, con José Luis Rodríguez Zapatero a la cabeza, ha liderado una auténtica ofensiva coordinada para impulsar la reactivación económica mundial, reformar el funcionamiento de los mercados financieros, modificar las instituciones que los regulan y evitar las tentaciones proteccionistas que ahoguen las posibilidades del comercio mundial de seguir creando riqueza en condiciones de equidad para todos los países y sus ciudadanos.

Sin embargo, Público atacó a los socialistas discordes con el mensaje "común” del oficialismo. Uno de ellos fue el presidente del Congreso de los Diputados, José Bono. En “Santa Maravillas de Bono” (14/XI/2008, p. 18) se le introduce como un dirigente "ambiguo" y desconcertante:

De todos es sabido que José Bono es al PSOE lo que Gallardón al PP, un verso suelto que a veces desafina entre sus propias filas. Sin embargo, ayer el grupo socialista dio un paso más al desvincularse de la última decisión del presidente del Congreso. La brecha la ha abierto la placa que recordará en la Cámara a Santa Maravillas de Jesús, que según la Iglesia católica sufrió ‘persecución religiosa’ durante la Guerra Civil.

\section{Análisis de resultados}

Público se identificó con diversas fórmulas expresivas, sin encasillarse estrictamente en una. Los rasgos "arrevistados" y vistosos de sus portadas, los titulares de tono "semiserio" y la ingente cantidad de elementos gráficos lo identifican como un "tabloide-cartel" dentro del modelo "popular-sensacionalista". Este formato es bastante común en el continente americano (Newsday, New York Post), donde es sinónimo de espectacularidad visual y textos provocativos, pero poco profundos. No obstante, al revisar las páginas interiores, determinamos que la cobertura de este diario no responde estrictamente a razones de "interés humano". Su sensacionalismo no estuvo centrado en la farándula o en personajes estrafalarios, sino en el 
acontecer político. Esta temática es predominante en sus portadas y en muchas de sus secciones, aunque teñida de tendenciosidad y polémica.

De esta manera, estamos ante una publicación que combinó el diseño cálido e impactante del sensacionalismo con ciertas dosis "informativas" y "editorializantes". Pese a esta desconcertante naturaleza, este diario no ocultó su interés por los sectores juveniles, a los cuales reconoce como sus principales lectores. Para lograr atraer a estos segmentos (caracterizados por su inconformismo y relativa conciencia política) Público aplicó una particular configuración de a) las secciones; b) las portadas; c) el lenguaje periodístico; y d) el tratamiento del acontecer político.

Con respecto al primer punto, los campos científicos, culturales y deportivos gozaron de mayor cantidad de páginas y de alarde gráfico que otras temáticas más serias. Más que traslucir rasgos consumistas o de mero entretenimiento cultural, esta tendencia informativa de Público se compenetraría, en cierta medida, con los fines del "periodismo de servicio", que se caracteriza por contenidos más cercanos a la realidad cotidiana del potencial lector.

En segundo lugar, las portadas se rigieron por una presentación amena que facilitaría la comprensión de sus textos. Asimismo, tuvieron la cualidad de albergar fotomontajes y elementos infográficos. Dentro de la primera página, ambos elementos visuales abandonaron su función decorativa articulando ágilmente la información con los gráficos, añadiendo cierto tono distendido y humorístico.

En tercer lugar, el lenguaje periodístico en las páginas políticas adquirió una gran libertad expresiva, dirigida a avivar la polémica y la ironía. Este estilo visceral se corresponde directamente con el ya expuesto en las portadas y, sobre todo, en los textos de la sección "Opinión”. La incidencia de coloquialismos y frases exclamativas, sobre todo en los titulares, aumentó el grado de informalidad y desenfado.

Sin embargo, al reseñar las actividades de la derecha política española, el buen humor y la comicidad se tornaron en agrios sarcasmos y crueles parodias. Así, las principales figuras del Partido Popular (Mariano Rajoy, Esperanza Aguirre, Alberto Ruiz-Gallardón, José María Aznar, entre otros) fueron objeto de caricaturización y de ataques a su gestión. El blanco preferido fue el presidente de dicha agrupación, quien recibió innumerables calificativos, citando su aparente incompetencia, su debilidad de liderazgo dentro del partido, su oportunismo ante la crisis financiera, entre otros. 


\section{Conclusiones}

Público comparte muchas afinidades con la fórmula "popular-sensacionalista”. Su apuesta incesante por la vistosidad cromática, el gigantismo tipográfico, los titulares de contenido "semiserio" son indudables. Dentro de ese esquema de diseño, la sección "Política” exhibió páginas atractivas, donde los textos periodísticos contaron con un generoso despliegue de elementos complementarios ${ }^{13}$ (despieces, infografías, entre otros). Muchos de ellos contendrían mapas, cuadros comparativos e incluso caricaturas con la finalidad de no generar pereza y aburrimiento en lectores ocupados o poco dispuestos a una lectura exigente. Para cautivar a los internautas, las cuñas de varios reportajes remitían a la página electrónica de Público, donde los interesados podían comentarla en la red.

Esta atención a las necesidades del lector también se vio reflejada en la extensa y variada política de promociones, de evolución casi intermitente desde sus primeros números. Si bien comenzó como una ambiciosa estrategia de marketing, los obsequios de libros y de material educativo multimedia se han convertido en una cualidad muy apreciada por sus consumidores, reforzando además el sello editorial de Público más allá de la circulación diaria de sus ejemplares.

Otro de los rasgos particulares de esta publicación fue la carencia de un espacio editorial ${ }^{14}$ en sus páginas. No obstante, esta ausencia fue compensada con una sección de opinión integrada por varias columnas de diversa naturaleza. Esta preferencia por el columnismo también se evidenció en el resto de las secciones, donde las principales informaciones importantes del día recibieron su correspondiente valoración y juicio mediante breves comentarios de los columnistas y jefes de área.

La delimitación entre la opinión y la información estuvo sujeta a una particular exégesis de los géneros periodísticos. En el suplemento especial, entregado en el primer número, se considera que el acto de opinar era "tomar partido, hacer una propuesta y buscar interlocutores para entablar un diálogo" (Público, 2007a: 40), mientras que la información política se centraría en todo aquello que afectase a los ciudadanos, más

13 El diseño de Público ha recibido varios reconocimientos internacionales (2008a: 60) por su tratamiento visual e infográfico: en la XVI Edición de los Premios Malofiej, fue el diario más galardonado, obteniendo seis preseas, luego del británico The Guardian. Asimismo, la Society for News Design (SND) galardonó la cobertura de este diario referida al calentamiento global. En septiembre del 2008 obtuvo nueve premios en la V Edición del Certamen $\tilde{\mathrm{N} H}$, que reunió a los mejores exponentes del diseño periodístico en España y Portugal.

14 El entonces director Ignacio Escolar (2007: web) explica tal ausencia: "Público no tendrá editoriales porque, en mi opinión, una sociedad anónima no puede tener opinión sobre nada. Las opiniones son de las personas físicas, no de las personas jurídicas, que -más que opiniones- lo que tienen son intereses. El editorial es una figura periodística que tenía sentido en el siglo XIX, cuando la opinión no era libre y a veces era necesario parapetarse tras la cabecera del diario, desde el anonimato, para opinar con mayor libertad. Ahora no tiene sentido". 
allá de las ambiciones de los políticos: "Lo que dicen las personas importantes no son noticias importantes, hay días en que ni siquiera son noticia. No seremos neutrales pero sí honestos” (2007a: 44).

Una exploración física del diseño revela la gráfica división de los géneros empleados mediante el uso constante de cartelas ${ }^{15}$ rojas, las cuales (a modo de encabezados o antetítulos) designaban a varios espacios como "crónicas" o "reportajes". Se asumía que la ausencia de dichas cartelas en otros textos determinaba su carácter exclusivamente "lineal” y “objetivo”. Sin embargo, este vistoso y didáctico sistema de clasificación resultó ser un ornamento arbitrario: muchos de los textos extraídos y presentados en esta investigación demostrarían el establecimiento de una engañosa división de géneros.

En esencia, el afán editorialista de este diario promovió la combinación de los hechos con juicios subjetivos tendenciosos dentro de las estructuras narrativas de las noticias y los reportajes objetivos. Establecemos esta conclusión general mediante las siguientes afirmaciones, repartidas en los cuatro vértices fundamentales de la casuística:

A) Sobre temáticas:

- “Satanización” de la ideología del PP (ultraconservador, xenófobo, neocon), que sufre una peligrosa fragilidad interna (Aguirre/Gallardón) y arrastra un anquilosado liderazgo sin visos de renovación.

- $\quad$ Crítica sistemática a la política exterior del ex presidente José María Aznar durante la VII Legislatura.

- $\quad$ Rajoy aparece como un personaje dedicado a "desgastar" al gobierno y como fuente de medidas "populistas” ante la crisis económica. Asimismo, es retratado como un líder poco carismático, cuestionado por sus propios partidarios (Aznar, Aguirre).

- Imagen positiva de Rodríguez Zapatero: líder internacional, gestor eficiente de medidas “anticrisis”. A diferencia de su antípodas del PP, resulta ser un dirigente carismático dentro del PSOE.

B) Sobre el abuso de citas:

- Se administraron de forma sensacionalista las citas directas (ataques ad hóminem, calificativos, parodias), canalizando apreciaciones categóricas y tendenciosas.

- $\quad$ No existió un afán de contextualizar las declaraciones: sólo se procuró formar un cúmulo abarrotado de entrecomillados, explotando el tono irónico y exclamatorio.

15 Son pequeños titulares que sirven para encuadrar noticias por temas o por géneros periodísticos. También se emplean para encabezar artículos de opinión en las páginas de información o los nombres fijos de colaboraciones o columnas habituales (Berrocal y Rodríguez-Maribona, 1998: 61). 
- Se enfatizaron ideas mediante la repetición de frases coloquiales: "Quita y pon”, "patriota de pacotilla", "arrimar el hombro".

- Esta práctica convierte a los redactores en meros altavoces repetidores, consolidando un pasivo y peligroso "periodismo de púlpito".

C) Sobre el lenguaje exclamatorio:

- Dominado por el tono apelativo, propio de los mensajes propagandísticos y doctrinarios. Proclive a incluir valoraciones afectivas.

- Intentó avivar la polémica política mediante ataques ad hóminem y el uso de calificativos desenfadados.

- Su sentido sarcástico, paródico e irónico primó sobre la imparcialidad y la prudencia informativa.

D) Sobre el editorialismo informativo:

- $\quad$ Promueve la inclusión de comentarios y frases de contenido valorativo en formatos objetivos, canalizando campañas proselitistas de manera encubierta.

- Su práctica implica la corrupción de la labor orientadora del periodista.

- $\quad$ No contribuye al desarrollo de los géneros periodísticos ni alienta la aparición de enfoques creativos responsables.

\section{Referencias bibliográficas}

Abril, Natividad (1999): Periodismo de opinión, Madrid: Síntesis.

Aguilera, Octavio (1990): Las ideologías en el periodismo, Madrid: Paraninfo.

Armañanzas, Emily y Díaz Noci, Javier (1996): Periodismo y argumentación: géneros de opinión, Bilbao: Servicio Editorial Universidad del País Vasco.

Armentia Vizuete, José Ignacio y Caminos Marcet, José (1998): La información: redacción y estructuras, Bilbao: Universidad del País Vasco.

- (2002): Fundamentos de periodismo impreso, Barcelona: Ariel. 
Berrocal, Salomé y Rodríguez-Maribona, Carlos (1998): Análisis básico de la prensa diaria. Manual para aprender a leer periódicos, Madrid: Universitas.

Borrat, Héctor (1989): El periódico, actor político, Barcelona: Gustavo Gili.

Cantavella Blasco, Juan y Serrano Oceja, José (coords.) (2004): Redacción para periodistas: informar e interpretar, Barcelona: Ariel.

- (2007): Redacción para periodistas: opinar y argumentar, Madrid: Universitas.

Casasús, Josep María y Núñez Ladevèze, Luis (1991): Estilos y géneros periodísticos, Barcelona: Ariel.

Edo, Concha (2003): Periodismo informativo e interpretativo. El impacto de Internet en la noticia, las fuentes y los géneros, Sevilla: Comunicación Social.

Escarpit, Roberto (1992): Teoría de la información y propaganda política, México D. F.: Fondo de Cultura Económica.

Escribano, Asunción (2006): Comentario de textos periodísticos: informativos, interpretativos y de opinión, Salamanca: Universidad de Salamanca

Escolar, Ignacio (2007): “Todo lo que siempre quiso saber sobre ‘Público'”. Página electrónica del diario Público. Consultado el 4/IX/2007. Disponible en: http://www.escolar.net/MT/archives/2007/09/todo-lo-que-siempre-quisosaber-sobre-publico.html.

Fontcuberta, Mar de (1995): La noticia: Pistas para percibir el mundo, Barcelona: Paidós.

Herrero Aguado, Carmen (1996): Periodismo político y persuasión, Madrid: Actas.

López Hidalgo, Antonio (2002): Géneros periodísticos complementarios. Una aproximación crítica a los formatos del periodismo visual, Sevilla: Comunicación Social.

Martínez Albertos, José Luis (2001): Curso general de redacción periodística: lenguaje, estilos y géneros periodísticos en prensa, radio, TV y cine, Madrid: Paraninfo-Thomson Learnings.

Muñoz Alonso, Alejandro (1989): Política y nueva comunicación, Madrid: Fundación para el Desarrollo del Conocimiento. Núñez Ladevèze, Luis (1995): Introducción al periodismo escrito, Barcelona: Ariel.

Parratt, Sonia (2003): Introducción al reportaje: antecedentes, actualidad y perspectivas, Santiago de Compostela: Universidade de Santiago.

Público, diario (números consultados correspondientes al trimestre septiembre-noviembre de 2008), Madrid: Mediapubli.

- (2007a): Suplemento especial “Hoy nace tu diario”. 26 de septiembre de 2007.

- (2008a): Suplemento especial “Primer Aniversario". 26 de septiembre de 2008.

Santamaría, Luisa (1990): Géneros para la persuasión en periodismo, Madrid: Fragua. 
Warren, Carl (1975): Géneros periodísticos informativos, Barcelona: A.T.E.

Yanes, Rafael (2004): Géneros periodísticos y géneros anexos. Una propuesta metodológica para el estudio de los textos publicados en prensa. Madrid, Fragua.

$150\left|n^{\circ} 10\right|$ doxa.comunicación 